\title{
Ground glass opacities: Imaging, pathology, and gene mutations
}

Fenghao Sun, MD, ${ }^{\mathrm{a}}$ Junjie Xi, MD, ${ }^{\mathrm{a}}$ Cheng Zhan, $\mathrm{PhD},{ }^{\mathrm{a}}$ Xiaodong Yang, MD, ${ }^{\mathrm{b}}$ Lin Wang, MD, Yu Shi, MD, ${ }^{\text {a }}$ Wei Jiang, MD, ${ }^{a}$ and Qun Wang, $\mathrm{MD}^{\mathrm{a}}$

\section{ABSTRACT}

Background: Lung cancer can be detected in its early stages with computed tomography (CT). Early lung adenocarcinoma often is displayed as ground glass opacity (GGO), an entity that has been well studied over the past decade. However, few studies have focused on the correlation between CT characteristics and pathologic subtype of GGO. We aimed to explore the correlation between CT characteristics, pathologic subtype, and gene mutation associated with GGO in an effort to aid in the treatment of lung adenocarcinoma.

Methods: In this retrospective study, patients with GGO who underwent surgery in our institution between 2013 and 2016 were included. Patients were divided into 2 groups on the basis of CT characteristics: group 1, diameter $<20 \mathrm{~mm}$ and solid component $<50 \%$; and group 2, diameter $\geq 20 \mathrm{~mm}$ or solid component $\geq 50 \%$. Differences in pathologic subtype and gene mutation pattern between groups were compared using the $\chi^{2}$ test. The correlation between pathologic subtype and epidermal growth factor receptor $(E G F R)$ mutation was also tested using the $\chi^{2}$ test.

Results: A total of 1018 cases (408 in group 1, 610 in group 2) were included; of these, 544 were tested for the EGFR gene mutation. There was a significant difference in predominant subtype $(P<.001)$ and all included subtypes $(P=.044)$ between the groups. Of 59 cases with the pathologic subtype of micropapillary or solid, 57 were in group 2. The EGFR gene mutation rate was significantly higher in group 2 than group $1(P<.001)$ and significantly correlated with pathologic subtype $(P<.001)$; adenocarcinoma in situ was the lowest $(31.4 \%)$ and papillary was the highest $(85.7 \%)$. EGFR mutation subtype did not significantly differ between groups $(P=.499)$.

Conclusions: CT characteristics of GGO significantly correlated with pathologic subtype and gene mutation rate. The EGFR mutation rate differed significantly among pathologic subtypes. GGOs with a diameter of $<20 \mathrm{~mm}$ and with a solid component $<50 \%$ seldom contain subtypes with poor prognosis (micropapillary and solid) and the EGFR mutation rate was significantly lower. (J Thorac Cardiovasc Surg 2018;156:808-13)

From the ${ }^{\mathrm{a}}$ Department of Thoracic Surgery, Zhongshan Hospital, Fudan University, Shanghai, China; and 'Eight-year Program Clinical Medicine, Grade of 2010, Shanghai Medical College, Fudan University, Shanghai, China.

This work was supported by the National Natural Science Foundation of China (grant numbers 81401875,81472225 , and 81370587), and the Natural Science Foundation of Shanghai, China (grant number 14ZR1406000).

Drs Sun and Xi contributed equally to this work.

Received for publication Aug 18, 2017; revisions received Feb 14, 2018; accepted for publication Feb 23, 2018; available ahead of print May 9, 2018.

Address for reprints: Qun Wang, MD, or Wei Jiang, MD, Department of Thoracic Surgery, Zhongshan Hospital, Fudan University, 180\#, Fenglin Rd, Xuhui District, Shanghai 200032, China (E-mail: wang.qun@zs-hospital.sh.cn or jiang.wei1@ zs-hospital.sh.cn).

$0022-5223 / \$ 36.00$

Copyright (c) 2018 by The American Association for Thoracic Surgery

https://doi.org/10.1016/j.jtcvs.2018.02.110

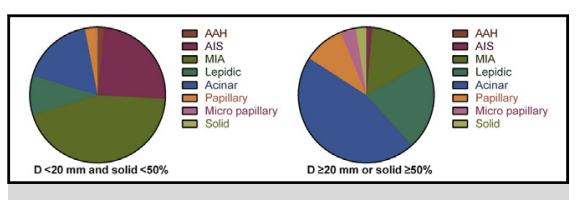

All pathologic subtypes in both groups.

Central Message

CT characteristics of GGO significantly correlated with pathologic subtype and gene mutation rate. Small GGOs seldom contain subtypes with poor prognosis.

\section{Perspective}

The EGFR mutation rate differed significantly among pathologic subtypes. Small GGOs seldom contain subtypes with poor prognosis. GGOs with a diameter $<20 \mathrm{~mm}$ and a solid component $<50 \%$ are more appropriate for sublobar resection than those with a diameter $>20 \mathrm{~mm}$ and a solid component $>50 \%$.

See Editorial Commentary page 814. 


\section{Abbreviations and Acronyms \\ AIS = adenocarcinoma in situ \\ $\mathrm{CT}=$ computed tomography \\ $E G F R=$ epidermal growth factor receptor \\ GGO = ground glass opacity \\ MIA = microinvasive adenocarcinoma \\ $\mathrm{NCCN}=$ National Comprehensive Cancer Network}

In 2011, a new international multidisciplinary classification system for lung adenocarcinoma was proposed by the International Association for the Study of Lung Cancer, the American Thoracic Society, and the European Respiratory Society. ${ }^{2}$ The histological subtype has significant influence on prognosis. Micropapillary and solid subtypes are correlated with poor prognosis. ${ }^{3-5}$ According to National Comprehensive Cancer Network (NCCN) guidelines, nodules $<2 \mathrm{~cm}$ and $\geq 50 \%$ ground glass appearance is the indication for sublobar resection. However, few studies have explored the correlation of imaging characteristics, pathologic subtype, and gene mutation in GGO. Somatic mutations of epidermal growth factor receptor (EGFR) are found in a significant proportion of lung adenocarcinoma. ${ }^{6}$ Still, the association between clinical and pathologic characteristics and subtypes of the EGFR mutation in GGO has not been well evaluated. In this study, we aimed to explore this association to investigate the NCCN guidelines for sublobar resection from a histological and gene perspective and hopefully aid in the treatment of lung adenocarcinoma.

\section{METHODS}

This study protocol was approved by the Ethics Committee of Zhongshan Hospital, Fudan University, Shanghai, China (approval number B2017-115). Written informed consent was obtained from all patients before surgery for the use of surgical samples and clinical information for medical research.

\section{Patients}

The indication of surgery for GGO patients were: (1) pure GGO $>20 \mathrm{~mm}$ or mixed GGO $\geq 10 \mathrm{~mm}$, (2) do not diminish during a 3-month follow-up, and (3) heart and lung function can tolerate surgery. We retrospectively reviewed the records of patients with GGO who underwent curative surgical resection at our institute between January 2013 and December 2016. Inclusion criteria were as follows: (1) pathologically confirmed primary lung adenocarcinoma or atypical adenomatous hyperplasia, and (2) R0 resection. Exclusion criteria were: (1) no pathologic subtype data, and (2) missing data. Sex, age, lesion diameter, diameter of the solid component, gene mutation, and pathologic subtype were analyzed.

\section{Analysis of EGFR Mutation}

Formalin-fixed, paraffin-embedded tissue sections of the resected tumors were used for the analysis of EGFR mutation. DNA extraction and analysis of exons $18,19,20$, and 21 were performed using the peptide nucleic acid-locked nucleic acid polymerase chain reaction clamp method by Mitsubishi Kagaku Bio-chemical Laboratories Inc (Tokyo, Japan).
TABLE 1. Clinical and pathologic characteristics of the 2 groups

\begin{tabular}{|c|c|c|c|}
\hline & Group 1 & Group 2 & $\begin{array}{c}P \\
\text { value }\end{array}$ \\
\hline Age, $y$ & $52 \pm 0.56$ & $59.2 \pm 0.414$ & $<.001$ \\
\hline $\begin{array}{l}\text { Sex, }(\%) \\
\text { Male } \\
\text { Female }\end{array}$ & $\begin{array}{l}104(10.22) \\
304(29.86)\end{array}$ & $\begin{array}{l}189(18.57) \\
421(41.36)\end{array}$ & .068 \\
\hline $\begin{array}{l}\text { Median of follow-up time before } \\
\text { surgery, mo }\end{array}$ & 4 & 2 & \\
\hline $\begin{array}{l}\text { Progression during follow-up, }(\%) \\
\text { With progression } \\
\text { Without progression }\end{array}$ & $\begin{array}{c}53(5.21) \\
355(34.87)\end{array}$ & $\begin{array}{c}78(7.66) \\
532(52.26)\end{array}$ & .986 \\
\hline $\begin{array}{l}\text { Gene mutation test, }(\%) \\
\text { Yes } \\
\text { No }\end{array}$ & $\begin{array}{l}196(19.25) \\
212(20.83)\end{array}$ & $\begin{array}{l}348(34.18) \\
262(25.74)\end{array}$ & .0006 \\
\hline $\begin{array}{l}\text { Predominant subtype, }(\%) \\
\text { AAH } \\
\text { AIS } \\
\text { MIA } \\
\text { Lepidic } \\
\text { Acinar } \\
\text { Papillary }\end{array}$ & $\begin{array}{c}7(0.69) \\
111(10.90) \\
203(19.94) \\
17(1.67) \\
66(6.48) \\
4(0.39)\end{array}$ & $\begin{aligned} 1 & (0.10) \\
12 & (1.18) \\
145 & (14.24) \\
65 & (6.39) \\
370 & (36.35) \\
17 & (1.67)\end{aligned}$ & $<.001$ \\
\hline $\begin{array}{l}\text { All pathologic subtype, }(\%) \\
\text { AAH } \\
\text { AIS } \\
\text { MIA } \\
\text { Lepidic } \\
\text { Acinar } \\
\text { Papillary } \\
\text { Micropapillary } \\
\text { Solid }\end{array}$ & $\begin{array}{c}7(0.69) \\
111(10.90) \\
203(19.94) \\
43(4.22) \\
79(7.76) \\
12(1.18) \\
1(0.10) \\
1(0.10)\end{array}$ & $\begin{array}{c}1(0.10) \\
12(1.18) \\
145(14.24) \\
198(19.45) \\
426(41.85) \\
91(8.94) \\
33(3.24) \\
24(2.36)\end{array}$ & .017 \\
\hline $\begin{array}{l}\text { Gene mutation, (\%) } \\
\text { Wild type } \\
A L K \\
B-R A F \\
\text { EGFR } \\
H E R-2 \\
K-R A S \\
P I K 3 C A \\
\text { RET } \\
\text { ROS-1 }\end{array}$ & $\begin{aligned} 95 & (17.46) \\
0 & (0.00) \\
2 & (0.37) \\
78 & (14.34) \\
13 & (2.39) \\
4 & (0.74) \\
0 & (0.00) \\
3 & (0.55) \\
1 & (0.18)\end{aligned}$ & $\begin{aligned} 97 & (17.83) \\
1 & (0.18) \\
1 & (0.18) \\
232 & (42.65) \\
5 & (0.92) \\
6 & (1.10) \\
1 & (0.18) \\
2 & (0.37) \\
3 & (0.55)\end{aligned}$ & $<.001$ \\
\hline
\end{tabular}

$A A H$, Atypical adenomatous hyperplasia; $A I S$, adenocarcinoma in situ; $M I A$, microinvasive adenocarcinoma; $A L K$, anaplastic lymphoma kinase; $B-R A F$, B-rapidly accelerated fibrosarcoma; $E G F R$, epidermal growth factor receptor; $H E R-2$, human epidermal growth factor receptor 2; K-RAS, Kirsten rat sarcoma viral oncogene homolog; PIK3CA, phosphatidylinositol-4,5-bisphosphate 3-kinase catalytic subuni alpha; $R E T$, ret proto-oncogene; $R O S-1$, c-ros oncogene 1 receptor tyrosine kinase.

\section{CT Characteristics and Pathology}

Thin-slice CT (1 mm per slice) was used to measure the GGO and consolidation component. GGO is defined as a misty increase in lung attenuation without obscuring the underlying vascular markings. The consolidation component is defined as an area of increased opacification that completely obscures the underlying vascular structures. The solid component ratio was calculated by dividing the maximum consolidation diameter by the maximum tumor dimension including ground glass part in the lung window. CT scans were reviewed and tumor sizes determined by 2 

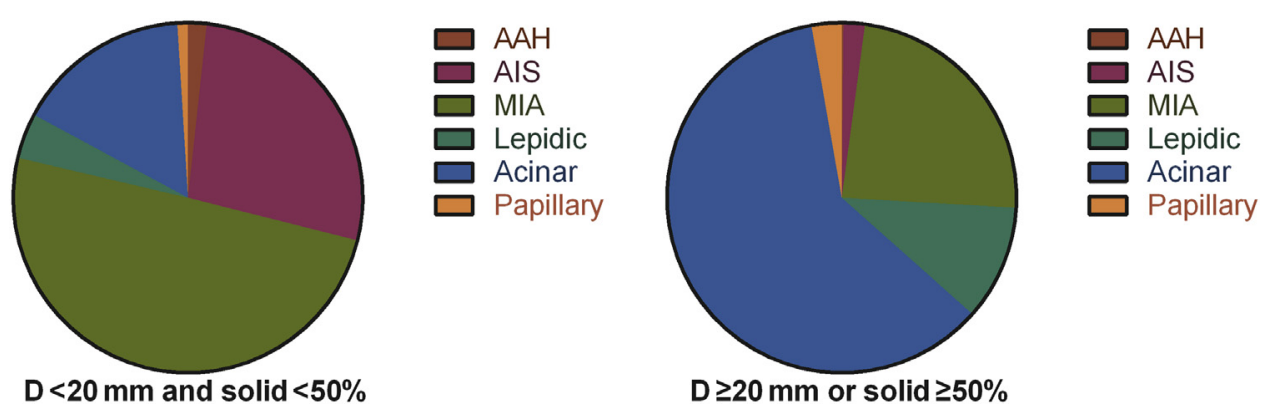

FIGURE 1. Predominant subtypes in both groups. AAH, Atypical adenomatous hyperplasia; $A I S$, adenocarcinoma in situ; MIA, microinvasive adenocarcinoma; $D$, diameter.

independent radiologists. Disagreements were resolved by consensus. Pathology and gene mutation results were acquired from pathology reports.

\section{Statistical Analysis}

Cases were separated into 2 groups on the basis of CT characteristics. Group 1 were patients with a diameter $<20 \mathrm{~mm}$ and a solid component $<50 \%$. Group 2 included patients with a diameter of $\geq 20 \mathrm{~mm}$ or a solid component of $\geq 50 \%$. Differences in pathologic subtype and gene mutation pattern between groups and the correlation between pathologic subtype and EGFR mutation were tested using the $\chi^{2}$ test or Fisher exact test. Statistical analyses were performed using $\mathrm{R}$ software, version 3.3.1 (http://www.rproject.org/). A $P$ value of $<.05$ was considered statistically significant.

\section{RESULTS}

A total of 1018 GGOs (408 in group 1, 610 in group 2) from 894 patients were included in this study. One hundred three patients had more than 1 GGO. As shown in Table 1, there was no significant difference between the 2 groups with regard to sex. There was a significant difference with regard to age between groups $(52 \pm 11.4$ vs $59.2 \pm 10.2$ years; $P<.001$ ).

\section{Correlation Between CT Characteristics and \\ Pathologic Subtypes}

Figure 1 shows the predominant subtypes in both groups. There were no cases of predominant subtypes with micropapillary or solid components in either group. Adenocarcinoma in situ (AIS) and microinvasive adenocarcinoma (MIA) accounted for most cases in group 1, whereas MIA and acinar accounted for a large part in group 2 . There was a statistically significant difference between groups with regard to predominant subtype $(P<.001)$.

Then, we analyzed the difference of all pathologic subtypes between groups (Figure 2). As shown in Table 2, only $2(2.3 \%)$ cases in group 1 had a micropapillary or solid component, versus $58(12.9 \%)$ in group 2 . The number of cases with micropapillary or solid components in group 2 was significantly more than that in group $1(P<.001)$.

\section{Correlation Between CT Characteristics and Gene Mutation}

Not all cases were tested for gene mutations. Figure 3 shows the pattern of gene mutations in both groups. In both groups, the wild type and EGFR mutations comprised nearly $90 \%$ of cases. However, the EGFR mutation rate was significantly higher in group 2 than in group $1(P<.001)$. The difference in the EGFR mutation site between groups was also tested (Figure 4). Mutations in exon 19 and 21 comprised most in both groups, without a significant difference between them $(P=.498)$.

\section{Correlation Between Pathologic Subtypes and EGFR Mutation}

The following analysis was focused on the EGFR mutation, which is the most frequent mutation in lung adenocarcinoma. Figure 5 shows the correlation between the predominant pathologic subtype and the EGFR mutation.
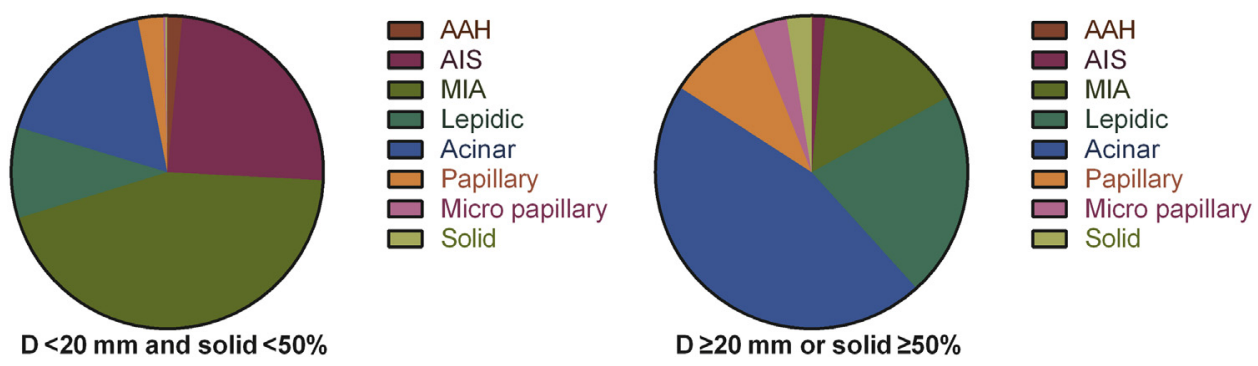

FIGURE 2. All pathologic subtypes in both groups. AAH, Atypical adenomatous hyperplasia; $A I S$, adenocarcinoma in situ; $M I A$, microinvasive adenocarcinoma; $D$, diameter. 
TABLE 2. Subgroup analysis of EGFR mutation rates of lepidic predominant cases

\begin{tabular}{lcc}
\hline & $\begin{array}{c}\text { With } \boldsymbol{E G F R} \\
\text { mutation }\end{array}$ & $\begin{array}{c}\text { Without } \boldsymbol{E G F R} \\
\text { mutation }\end{array}$ \\
\hline $\begin{array}{c}\text { Lepidic predominant with } \\
\text { other minor subtypes }\end{array}$ & 21 & 6 \\
$\begin{array}{l}\text { Only lepidic subtype } \\
\text { EGFR, Epidermal growth factor receptor }\end{array}$ & 3 & 6 \\
\hline
\end{tabular}

$E G F R$, Epidermal growth factor receptor.

The EGFR mutation rate of AIS, MIA, lepidic, acinar, and papillary subtypes was $31.4 \%, 38.5 \%, 67.6 \%, 70.1 \%$, and $85.7 \%$, respectively $(P<.001)$.

To determine the reason for the significant difference in $E G F R$ mutation rate between MIA and lepidic subtypes, we further analyzed the latter (lepidic). As shown in Table 2, the EGFR mutation rate in lepidic subtypes was $33.3 \%$ (close to the EGFR mutation rate of MIA), compared with $77.8 \%$ in all other cases.

\section{DISCUSSION}

Today, GGO is becoming an increasingly common indication for lung surgery. However, the extent of surgery is quite controversial. ${ }^{7-11}$ Wedge resection, segmentectomy, and lobectomy are all currently used to treat GGO. Video 1 shows a sublobar resection performed in our center. In this study, we separated all patients into 2 groups according to CT characteristics (diameter $<20 \mathrm{~mm}$ and solid component $<50 \%$ as group 1 ; diameter $\geq 20 \mathrm{~mm}$ or solid component $\geq 50 \%$ as group 2 ) and try to explore the differences in pathology and gene mutation patterns between these 2 groups. According to NCCN guidelines, the indication for sublobar resection is a peripheral nodule $<2 \mathrm{~cm}$ in size with at least 1 of the following: (1) pure bronchioalveolar carcinoma histology, (2) nodule with $\geq 50 \%$ ground glass appearance on CT imaging, and (3) radiologic surveillance confirming a long doubling time ( $>400$ days), and it is the reason that the 2 groups were separated at the cut point of $2 \mathrm{~cm}$ and $50 \%$ solid component. ${ }^{12}$

Most lung adenocarcinomas show heterogeneous histological patterns. ${ }^{13}$ In one lesion, there could be a predominant subtype and several minor components. In this study, all pathologic subtypes were included to explore their correlation with CT characteristics. None of the cases in our cohort had predominant micropapillary or solid subtypes. As for all components, only $2.3 \%$ of group 1 patients had a micropapillary or solid component, a significantly lower rate than in group $2(12.9 \%)$. A previous study showed that the prognosis for lepidic predominant adenocarcinoma in stage I patients was excellent, whereas that of the solid and micropapillary subtypes were poor. ${ }^{13-19}$ The presence of the micropapillary subtype was a poor prognostic factor. ${ }^{5}$ Moreover, our former study showed that the rate of lymph node metastasis was very low in peripheral lung cancers $<20 \mathrm{~mm}$ in size. ${ }^{20}$ Thus, lesions with a diameter $<20 \mathrm{~mm}$ in size, and a solid component $<50 \%$ have a better prognosis than those with a diameter $>20 \mathrm{~mm}$ and with a solid component $>50 \%$.

An activated mutation of the EGFR gene was first reported in $2004 .^{21-23}$ Since then, the biologic and clinical characteristics of the EGFR mutation have been extensively studied. ${ }^{24,25}$ EGFR mutations are more prevalent in those of Asian ethnicity. ${ }^{24,25}$ It has been reported that $47 \%$ to $64 \%$ of patients from East Asian regions with lung adenocarcinomas harbored EGFR mutations. ${ }^{26}$ However, most studies focused on advanced lung adenocarcinoma. In this study, we analyzed the gene mutation pattern in early stage lung adenocarcinoma. According to our results, $39.4 \%$ of cases in group 1 and $66.7 \%$ of those in group 2 harbored EGFR mutations, consistent with previous studies ${ }^{26}$ and the difference between the groups was statistically significant $(P<.001)$. Furthermore, we also analyzed EGFR mutations in different pathologic subtypes. The EGFR mutation rate was $30 \%$ to $40 \%$ in AIS and MIA subtypes, but as high as $70 \%$ to $80 \%$ in lepidic, acinar, and papillary subtypes. Because MIA was defined as a $\leq 3 \mathrm{~cm}$ lepidic predominant tumor with $\leq 5-\mathrm{mm}$ invasion, we investigated why the EGFR mutation rate was much higher than that in MIA. Our results showed that the EGFR mutation rate of lesions with only the lepidic component was significantly higher than that of other components.
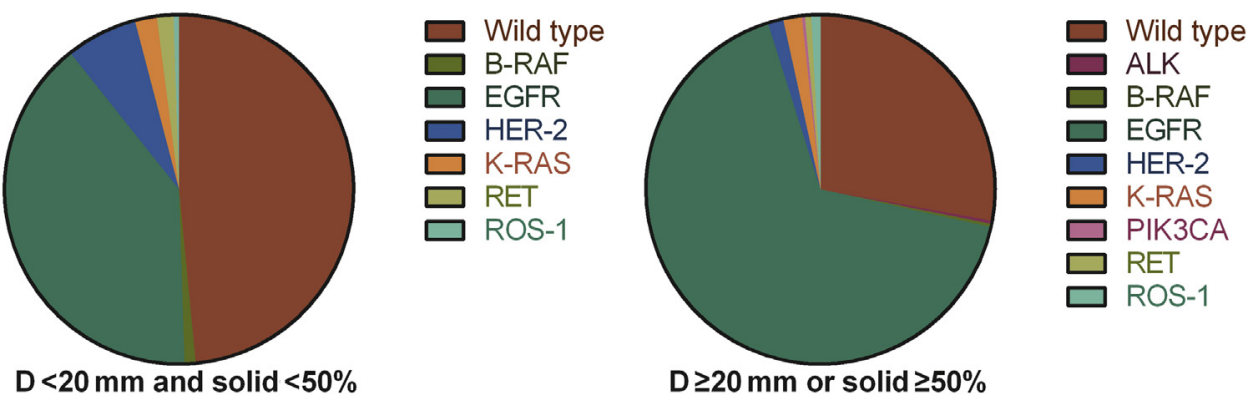

FIGURE 3. Gene mutation pattern in both groups. $B-R A F$, B-rapidly accelerated fibrosarcoma; $E G F R$, epidermal growth factor receptor; $H E R-2$, human epidermal growth factor receptor 2; $K$-RAS, Kirsten rat sarcoma viral oncogene homolog; $R E T$, ret proto-oncogene; ROS-1, c-ros oncogene 1 receptor tyrosine kinase; $D$, diameter; $A L K$, anaplastic lymphoma kinase; $P I K 3 C A$, phosphatidylinositol-4,5-bisphosphate 3-kinase catalytic subunit alpha. 

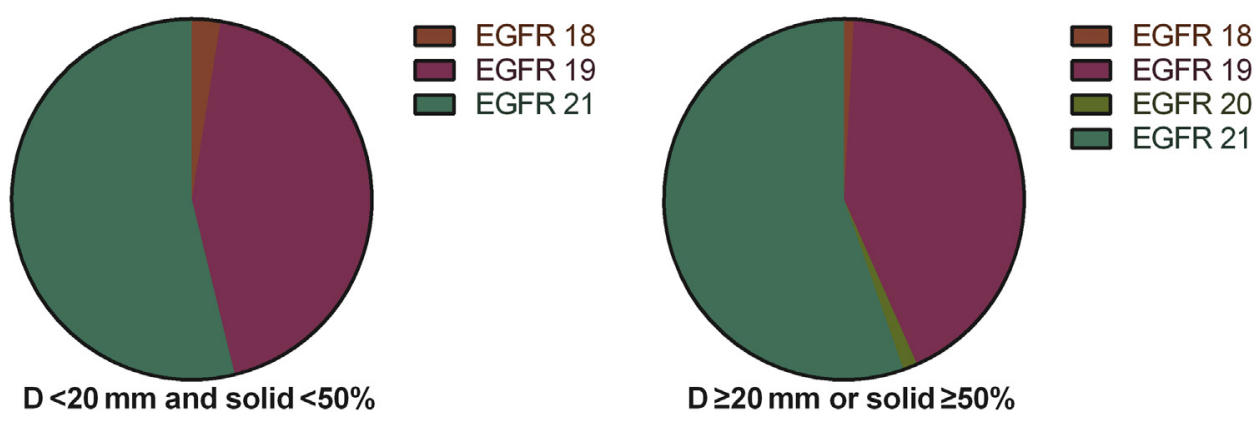

FIGURE 4. $E G F R$ mutation site in both groups. EGFR, Epidermal growth factor receptor; $D$, diameter.

This result indicates that the EGFR mutation rate was lower in cancers with lepidic components but higher in those with acinar and papillary components. There results imply that $E G F R$ mutations not only function in tumor genesis ${ }^{27}$ but are also generated during tumor development. In the era before targeted therapy, which was seldom used in earlystage lung adenocarcinoma, EGFR overexpression correlated with a poor prognosis. ${ }^{28-30}$

Besides size and solid component, the prognostic value of other factors such as pleural tag, presence or absence of lobulation, and air bronchogram has been evaluated extensively. ${ }^{31-34}$ However, the studies came to truly mixed results. Moreover, these factors are rather subjective and hard to quantify. Therefore, these factors were not considered in the study. There are several limitations of this study. First, only patients from a single center were included in this study. Our results need to be further validated in a multicenter study. Because EGFR mutation rate is different between East ethnicity and West ethnicity,

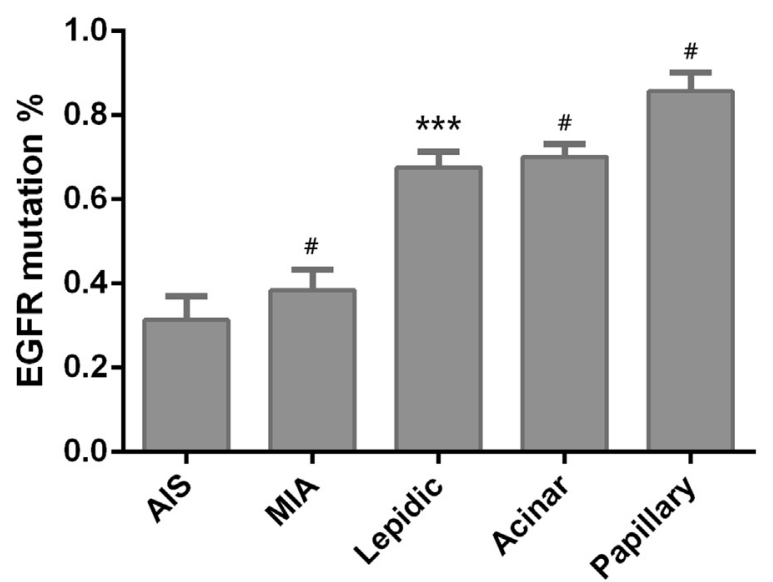

FIGURE 5. Correlation between the predominant pathologic subtype and EGFR mutation rate. EGFR, Epidermal growth factor receptor; $A I S$, adenocarcinoma in situ; MIA, microinvasive adenocarcinoma. $* * * P<.001$; $\# P>.05$. how EGFR mutation and pathologic subtypes are correlated in West population needs further research. Second, the 2 groups were not completely homogeneous in age and this might cause bias and influence the results. Third, not all patients were tested for EGFR mutation and not all GGO patients received surgery. This nonrandom and systematic difference in missing EGFR status between groups highly biases the results of the analyses. Therefore, a prospective, randomized study is needed to further validate our results. Fourth, no long-term data were analyzed in this study. Discussions regarding prognosis were on the basis of indirect evidence of other studies. To further explore this issue, a long-term follow-up is needed.

\section{CONCLUSIONS}

GGOs with a diameter of $<20 \mathrm{~mm}$ and a solid component of $<50 \%$ differs significantly from GGOs with a diameter $>20 \mathrm{~mm}$ or a solid component of $>50 \%$ in pathology and gene mutation patterns. The EGFR mutation rate varies significantly in cases with different predominant subtypes.

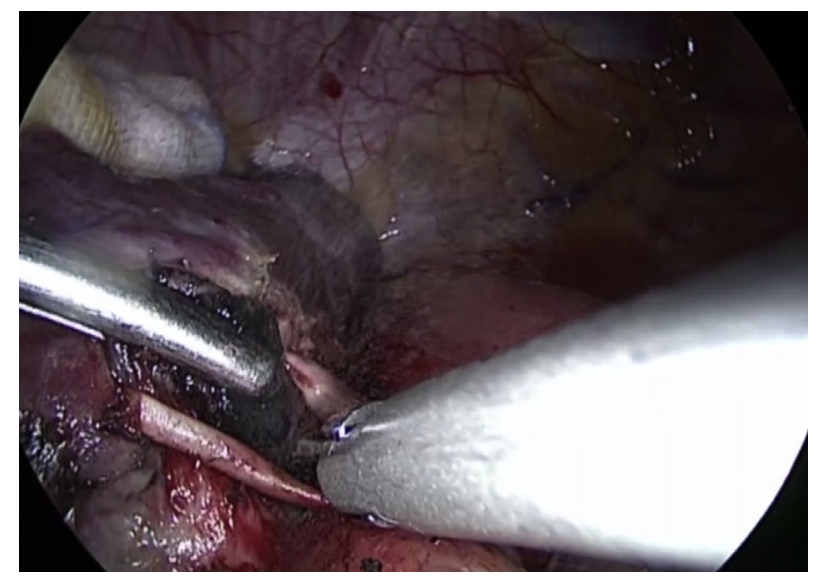

VIDEO 1. Segmentectomy of left upper lobe $\mathrm{S} 1+2+3$. Video available at: https://www.jtcvs.org/article/S0022-5223(18)30941-3/fulltext. 


\section{Conflict of Interest Statement \\ Authors have nothing to disclose with regard to commercial support.}

The authors thank International Science Editing Co for the language editing service.

\section{References}

1. Lee HY, Choi YL, Lee KS, Han J, Zo JI, Shim YM, et al. Pure ground-glass opacity neoplastic lung nodules: histopathology, imaging, and management. AJR Am J Roentgenol. 2014;202:W224-33.

2. Travis WD, Brambilla E, Noguchi M, Nicholson AG, Geisinger KR, Yatabe Y, et al. International Association for the Study of Lung Cancer/American Thoracic Society/European Respiratory Society International Multidisciplinary Classification of Lung Adenocarcinoma. J Thorac Oncol. 2011;6:244-85.

3. Amin MB, Tamboli P, Merchant SH, Ordóñez NG, Ro J, Ayala AG, et al. Micropapillary component in lung adenocarcinoma: a distinctive histologic feature with possible prognostic significance. Am J Surg Pathol. 2002;26:358-64.

4. Miyoshi T, Satoh Y, Okumura S, Nakagawa K, Shirakusa T, Tsuchiya E, et al. Early-stage lung adenocarcinomas with a micropapillary pattern, a distinct pathologic marker for a significantly poor prognosis. Am J Surg Pathol. 2003;27: 101-9.

5. Cha MJ, Lee HY, Lee KS, Jeong JY, Han J, Shim YM, et al. Micropapillary and solid subtypes of invasive lung adenocarcinoma: clinical predictors of histopathology and outcome. J Thorac Cardiovasc Surg. 2014;147:921-8.

6. Cancer Genome Atlas Research Network. Comprehensive molecular profiling of lung adenocarcinoma. Nature. 2014;511:543-50 [erratum in 2014;514:262].

7. Aokage K, Saji H, Suzuki K, Mizutani T, Katayama H, Shibata T, et al. A nonrandomized confirmatory trial of segmentectomy for clinical T1N0 lung cancer with dominant ground glass opacity based on thin-section computed tomography (JCOG1211). Gen Thorac Cardiovasc Surg. 2017;65:267-72.

8. Kato H, Oizumi H, Suzuki J, Hamada A, Watarai H, Nakahashi K, et al. Thoracoscopic wedge resection and segmentectomy for small-sized pulmonary nodules. J Vis Surg. 2017;3:66.

9. Koike T, Kitahara A, Sato S, Hashimoto T, Aoki T, Koike T, et al. Lobectomy versus segmentectomy in radiologically pure solid small-sized non-small cell lung cancer. Ann Thorac Surg. 2016;101:1354-60.

10. Tsutani Y, Miyata Y, Nakayama H, Okumura S, Adachi S, Yoshimura M, et al. Appropriate sublobar resection choice for ground glass opacity-dominant clinical stage IA lung adenocarcinoma: wedge resection or segmentectomy. Chest. 2014; 145:66-71.

11. Kodama K, Higashiyama M, Okami J, Tokunaga T, Imamura F, Nakayama T, et al. Oncologic outcomes of segmentectomy versus lobectomy for clinical T1a N0 M0 non-small cell lung cancer. Ann Thorac Surg. 2016;101:504-11.

12. Ettinger DS, Akerley W, Bepler G, Blum MG, Chang A, Cheney RT, et al. Nonsmall cell lung cancer. J Natl Compr Canc Network. 2010;8:740-801.

13. Travis WD, Brambilla E, Nicholson AG, Yatabe Y, Austin JH, Beasley B, et al. The 2015 World Health Organization classification of lung tumors: impact of genetic, clinical and radiologic advances since the 2004 classification. J Thorac Oncol. 2015;10:1243-60.

14. Yeh Y, Kadota K, Nitadori J, Sima CS, Rizk NP, Jones DR, et al. International Association for the Study of Lung Cancer/American Thoracic Society/European Respiratory Society classification predicts occult lymph node metastasis in clinically mediastinal node-negative lung adenocarcinoma. Eur J Cardiothorac Surg. 2015;49:e9-15.

15. Kadota K, Villena-Vargas J, Yoshizawa A, Motoi N, Sima CS, Riely GJ, et al. Prognostic significance of adenocarcinoma in situ, minimally invasive adenocarcinoma, and nonmucinous lepidic predominant invasive adenocarcinoma of the lung in patients with stage I disease. Am J Surg Pathol. 2014; 38:448.

16. Song Z, Zhu H, Guo Z, Wu W, Sun W, Zhang Y. Prognostic value of the IASLC/ ATS/ERS classification in stage I lung adenocarcinoma patients—based on a hospital study in China. Eur J Surg Oncol. 2013;39:1262-8.

17. Tsuta K, Kawago M, Inoue E, Yoshida A, Takahashi F, Sakurai H, et al. The utility of the proposed IASLC/ATS/ERS lung adenocarcinoma subtypes for disease prognosis and correlation of driver gene alterations. Lung Cancer. 2013;81: 371-6.

18. Russell PA, Wainer Z, Wright GM, Daniels M, Conron M, Williams RA. Does lung adenocarcinoma subtype predict patient survival?: A clinicopathologic study based on the new International Association for the Study of Lung Cancer/American Thoracic Society/European Respiratory Society international multidisciplinary lung adenocarcinoma classification. J Thorac Oncol. 2011;6: 1496-504.

19. Yoshizawa A, Sumiyoshi S, Sonobe M, Kobayashi M, Fujimoto M, Kawakami F, et al. Validation of the IASLC/ATS/ERS lung adenocarcinoma classification for prognosis and association with EGFR and KRAS gene mutations: analysis of 440 Japanese patients. J Thorac Oncol. 2013;8:52-61.

20. Wang L, Jiang W, Zhan C, Shi Y, Zhang Y, Lin Z, et al. Lymph node metastasis in clinical stage IA peripheral lung cancer. Lung Cancer. 2015;90:41-6.

21. Lynch TJ, Bell DW, Sordella R, Gurubhagavatula S, Okimoto RA Brannigan BW, et al. Activating mutations in the epidermal growth factor receptor underlying responsiveness of non-small-cell lung cancer to gefitinib. $N$ Engl J Med. 2004;350:2129-39.

22. Pao W, Miller V, Zakowski M, Doherty J, Politi K, Sarkaria I, et al. EGF receptor gene mutations are common in lung cancers from "never smokers" and are associated with sensitivity of tumors to gefitinib and erlotinib. Proc Natl Acad Sci U S A. 2004;101:13306-11.

23. Paez JG, Jänne PA, Lee JC, Tracy S, Greulich H, Gabriel S, et al. EGFR mutations in lung cancer: correlation with clinical response to gefitinib therapy. Science. 2004;304:1497-500.

24. Kosaka T, Yatabe Y, Onozato R, Kuwano H, Mitsudomi T. Prognostic implication of EGFR, KRAS, and TP53 gene mutations in a large cohort of Japanese patients with surgically treated lung adenocarcinoma. J Thorac Oncol. 2009;4:22-9.

25. Mitsudomi T, Kosaka T, Endoh H, Horio Y, Hida T, Mori S, et al. Mutations of the epidermal growth factor receptor gene predict prolonged survival after gefitinib treatment in patients with non-small-cell lung cancer with postoperative recurrence. J Clin Oncol. 2005;23:2513-20.

26. Shi Y, Au JS, Thongprasert S, Srinivasan S, Tsai C, Khoa MT, et al. A prospective, molecular epidemiology study of EGFR mutations in Asian patients with advanced non-small-cell lung cancer of adenocarcinoma histology (PIONEER). J Thorac Oncol. 2014;9:154-62.

27. Chou YT, Lin HH, Lien YC, Wang YH, Hong CF, Kao YR, et al. EGFR promotes lung tumorigenesis by activating miR-7 through a Ras/ERK/Myc pathway that targets the Ets2 transcriptional repressor ERF. Cancer Res. 2010;70:8822-31.

28. Hirsch FR, Varella-Garcia M, Bunn PA Jr, Di Maria MV, Veve R, Bremmes RM, et al. Epidermal growth factor receptor in non-small-cell lung carcinomas: correlation between gene copy number and protein expression and impact on prognosis. J Clin Oncol. 2003;21:3798-807.

29. Nicholson RI, Gee J, Harper ME. EGFR and cancer prognosis. Eur J Cancer. 2001;37:9-15.

30. Ohsaki Y, Tanno S, Fujita Y, Toyoshima E, Fujiuchi S, Nishigaki Y, et al Epidermal growth factor receptor expression correlates with poor prognosis in non-small cell lung cancer patients with p53 overexpression. Oncol Rep. 2000; 7:603-10.

31. Moon Y, Sung SW, Lee KY, Sim SB, Park JK. Pure ground-glass opacity on chest computed tomography: predictive factors for invasive adenocarcinoma. J Thorac Dis. 2016;8:1561-70.

32. Takashima S, Maruyama Y, Hasegawa M, Yamanda T, Honda T, Kadoya M, et al Prognostic significance of high-resolution CT findings in small peripheral adenocarcinoma of the lung: a retrospective study on 64 patients. Lung Cancer. 2002; 36:289-95.

33. Takashima S, Maruyama Y, Hasegawa M, Saito A, Haniuda M, Kadoya M. Highresolution CT features: prognostic significance in peripheral lung adenocarcinoma with bronchioloalveolar carcinoma components. Respiration. 2003;70: 36-42.

34. Honda T, Kondo T, Murakami S, Saito H, Oshita F, Ito H, et al. Radiographic and pathological analysis of small lung adenocarcinoma using the new IASLC classification. Clin Radiol. 2013;68:e21-6.

Key Words: GGO, imaging characteristics, pathologic subtype, EGFR mutation 